neuromuscular transmission. Our experience, like that of Martinez and Jimenez, indicates that these patients may never demonstrate clinical manifestations of myasthenia gravis, thus therapeutic decisions should be made based on the clinical findings, rather than EMG abnormalities.

DONALD B SANDERS

JAMES F HOWARD, JR

Division of Neurology,

Duke University Medical Center,

Box 3403,

Durham,

North Carolina 27710, USA, and Department of Neurology,

University of North Carolina,

Chapel Hill, North Carolina 27514, USA.

\section{Stridor during dystonia phases of Parkinson's disease}

Sir: Doctors Corbin and Williams' report of respiratory stridor co-occurring with limb and orofacial dystonia in two patients with idiopathic Parkinson's disease is noteworthy. ${ }^{1}$ However, their statement that " ... spasmodic dysphonia is now recognised as being a form of focal dystonia of the laryngeal muscles" (p. 821) needs clarification.

The cardinal signs of spastic (spasmodic) dysphonia, principally (1) intermittent or regular adductor voice arrests secondary to vocal fold/laryngeal hyperadduction, (2) moments of strained, effortful vocal quality interspersed within apparent normal phonation, and (3) intermittent or regular breathy moments secondary to abductory glottal arrests may represent psychogenicity, essential tremor and, as implied by Corbin and Williams, other disorders of movement. ${ }^{28}$

Co-occurring impairment of one or more of the other components of motor speech, namely articulation, resonation, respiration, and prosody (speech rhythm) is consistent with dysarthria rather than a focal laryngeal disorder. $^{2 \text { 7-9 }}$

The response of spastic dysphonia to treatment seems to depend upon aetiology, type of disorder (adductor, abductory, mixed), and mode of therapy. ${ }^{4} 7$

For those types of spastic dysphonia for which a recognisable aetiology cannot be identified, the term "idiopathic spastic dysphonia" has been recommended along with regular follow-up, which may eventually reveal an underlying substrate for the disorder. ${ }^{2-4}$

DAVID E HARTMAN

Department of Neurology, Gundersen Clinic, 1836 South Avenue,

La Crosse,

Wisconsin 54601, USA.

\section{References}

1 Corbin DOC, Williams HC. Stridor during dystonic phases of Parkinson's disease. $J$ Neurol Neurosurg Psychiatry 1987;50:821.

2 Aronson AE. Clinical Voice Disorders. 2nd ed. New York: Thieme Inc, 1985.

3 Hartman DE, Abbs JH. Clinical investigations of adductor spastic dysphonia. Ann Otol Rhinol Laryngol (in press).

4 Aronson AE, Hartman DE. Adductor spastic dysphonia as a sign of essential (voice) tremor. J Speech Hear Disord 1981;46:52-8.
5 Hartman DE, Aronson AE. Clinical investigations of intermittent breathy dysphonia. $J$ Speech Hear Disord 1981;46:428-32.

6 Marsden CD, Sheehy MP. Spastic dysphonia, Meige disease, and torsion dystonia. Neurology 1982;32:1202-3.

7 Hartman DE, Abbs JH. The Dysarthrias of Movement Disorders. In: Jankovic J, Tolsa E, eds. Facial Dyskinesias: Advances in Neurology. New York: Raven Press (in press).

8 Hartman DE. Neurogenic dysphonia. Ann Otol Rhinol Laryngol 1984;93:57-64.

9 Darley FL, Aronson AE, Brown JR. Motor Speech Disorders. Philadelphia: WB Saunders, 1975.

Corbin and Williams reply:

Sir: Dr Hartman reminds us of the possible mechanisms of vocal cord dysfunction in spasmodic dysphonia; however, in our final paragraph $^{1}$ we sought to emphasise the need for clinicians to consider dystonia as a cause of what may otherwise be an enigmatic disorder; we refer not only to some cases of spasmodic dysphonia but also to problems such as piano-player's dystonia and the occupational dystonias. ${ }^{2}$ Many such cases were previously classified as hysterical. Dr Hartman's policy of accepting that some cases of spasmodic dysphonia lack recognisable aetiology is safer in that it does not deny the possible existence of an organic cause.

\section{References}

1 Corbin DOC, Williams AC. Stridor during dystonic phases of Parkinson's disease. $J$ Neurol Neurosurg Psychiatry 1987;50:821-2.

2 Lees AJ. Tics and Related Disorders. London: Churchill Livingstone, 1985:166.

\section{Book reviews}

Neurological Disorders. (Treatment in Clinical Medicine series.) By D Parkes, P Jenner, D Rushton, C David Marsden. (Pp 227; £38.00.) London: Springer-Verlag, 1987.

This is the fifth monograph in a series on management and treatment in specialities in medicine and serves as a perfect riposte to those who would believe that the neurologist has a major role in diagnosis but only a minor role in therapy. It contains a practical approach to major neurological disorders which is spiced by the pharmacological expertise of Dr Jenner in explaining not only when, but why, a particular agent should be prescribed.

The initial chapter is a review of the actions of drugs on the nervous system and briefly considers the role of the blood brain barrier. It contains useful tables of drugs which are agonists and antagonists for the various neuro-transmittor receptors and examples of compounds which act upon specific receptor sub-types. There follow chapters on each of the common neurological disorders with the appropriate therapy and, where known, a summary of their mode of action. The authors' own interest and expertise in the treatment of movement disorders and sleep disorders is apparent in these, the best, chapters in the book and the whole provides a useful practical guide to logical therapy in neurological disorders. Inevitably the particular biases of the authors are revealed and not everyone will agree with their suggestion that steroids have a role in ischaemic stroke. Indeed the authors seem somewhat uncertain themselves in that on one page they state "it may therefore be beneficial to treat focal oedema around an infarct using osmotic diuretics or steroids" and on the next page "postinfarction oedema does not respond to steroids".

In the chapter on infections it would have been useful to have a suggestion as to the most reasonable combination therapy in the infant, adult or aged patient presenting with a presumed but unidentified or partially treated bacterial meningitis rather than the bald statement that therapy "depends on isolation of the causative organism". No 
mention is made in this chapter of the treatment of anaerobic infections other than in the context of brain abcess.

References are not interspersed in the text but individual chapters end with a list of suggestions for further reading including review articles. The book is primarily intended for physicians in general medicine and neurologists in training, an aim in which it should certainly succeed.

DAVID BATES

Neuromuscular Disorders: A Guide for Patient and Family. By Steven P Ringel. (Pp 169; $\$ 13.00 \mathrm{p} / \mathrm{b} ; \$ 20.00 \mathrm{~h} / \mathrm{b}$.) New York: Raven Press, 1987.

This book is designed to provide information for patients with neuromuscular discases and their families "so that they may circumvent some of the 'road blocks' in the health care system and so profit from the many medical advances available today". Professor Ringel is Director of the Neuromuscular Disease Clinic in Denver, Colorado and he has written a short readable book which is packed with insights and tips about the management of neuromuscular disease. The first 40 or so pages are brief descriptions of nerve and muscle and the diseases which affect them. There follows a chapter on genetic counsclling. The following 70 pages concern therapy (imagine that distribution in a neurology textbook!) and include chapters on physical therapy, bracing and surgery, aids to daily living, respiratory and speech therapy (the former including a discussion on the indications for ventilation), nutrition and exercise, drugs and emotional adjustment to disability. Two short sections on educational opportunities and various government and community resources complete the book-these latter chapters will be of limited interest to the UK reader since they apply specifically to the US.

Who can benefit from this book? Some of our patients and their relatives (notably the parents of boys with Duchenne dystrophy) will certainly learn more about thcir condition. For example, sound advice is often lacking about the type of foods most appropriate in neurogenic dysphagia; patients battle to find out by bitter experience and the alternatives to choking may never be discussed. Relatives are frequently not taught how to do a Hcimlich manocuvre; it may not always work but it often does and it relieves that intense feeling of helplessness which relatives feel when faced with acute aspiration.
The decision about whether or not to be ventilated is an issue nowadays - one which it is appropriate to talk about to the patient and family. Doctors and "health care providers" too may find much valuable advice here.

This book is helpful because it discusses many issues of therapy in an open and informed way. It will raise the expectations of patients as to what they may expect of their "specialist" doctors and the paramedical departments. It will help to banish finally the notion that any neuromuscular disease is untreatable and I commend it to all who look after patients with these conditions and to the many patients who wish for more information but cannot get it in the clinic.

CM WILES

Amyotrophic Lateral Sclerosis: A Guide to Patient Care. Edited by James T Caroscio. (Pp 360; DM 58.00.) Stuttgart: Georg Thieme Verlag, 1987.

This is obligatory reading for every neurologist. To quote the editor: "Physicians have a responsibility to care for patients with incurable diseases. The negative emotional responses of avoidance, rejection, inadequacy, frustration and feelings of impotence and loss of control that ALS brings out in physicians have resulted in the common practice of telling the patient with ALS: 'There is nothing that can be done. Go home, and prepare to die." "

It is because neurology is more than diagnosis that this book is essential reading. Of the 21 chapters, only four are concerned with purely medical considerations. The chapter on ethical issues by the editor puts in a nutshell what should be done regarding telling the patient about this fatal disease. Three of the chapters concern swallowing and feeding problems; four are concerned with physiotherapy and the various devices that can be used to help, while other chapters concern the psychological, sociological and nursing requirements. There is also a chapter on communication problems, the final chapter being one on voluntary organisations that help with this difficult disease. There are two chapters on the use of machines when patients develop respiratory failure, and these are perhaps not strictly relevant to practice in the United Kingdom. This difference in management between the United States and the United Kingdom is of great interest, and probably not dependent solely on the financial pattern of health ci্̛re

The editor, who tragically died shơ before its publication, was in charge of special clinic for MND patients at Mồn Sinai Hospital in New York, and deveec his life to this one disease. There are of similar centres in Chicago, Philadelphia 7 hic Miami, all supported by charitable bołfes The book is soft-backed and costs less than $£ 20$. For anyone dealing with this sad diforder, it is the best buy on the market.

F CLIFFORD F甲SE

움

Sleep and its Disorders in Children. Edite $\oiint_{\text {by }}$ Christian Guilleminault. (Pp 334; \$42 80.) New York: Raven Press, 1986.

This book about sleep in children is equally about parents fighting with their childreffat bedtime and again in the middle of the nim t. Most of the 20 authors work in sleep labơratories or departments of psychiatry, not $\mathrm{Bge}$ diatric clinics. There is a slant towartds American children. The book is in two parts-part 1 "presents normative dat: क्ञ⿰冫欠 part 2 is dedicated to pathological ph ena"-which, translated, means there Gre 128 pages on normal sleep habits, anfl $\$ 79$ pages about colicky infants and problems such as the sleep of children with epthe mental retardation and "brain-impairment"-whatever that may be.

A lot of the book is valuable, with $\mathrm{excel}$ lent and full documentation of matution of slecp and breathing patterns throgh infancy and childhood to adolescence. The establishment of circadian control is discussed in detail, and paralleling these stuches there are sections about normal psyc⿻一㇂㇒. -

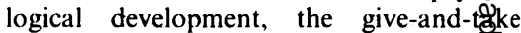
relationship between infants and parents well as about social and psychiatric factors that disturb the slecp of children. Sectians on disease are especially well done, including those on narcolepsy, sleep apnoea and offrer respiratory disorders in children, although here the causes, pathophysiology and magnagement are not very different from those adults. Guilleminault's wide experiencesof infantile sleep apnoea and SIDS, as welBas his studies of infective mononucleosisin adolescence, deserve special recognition. 을

There are a number of problems. The overall standard of writing is laboured, with a fair amount of jargon, making detaited reading difficult. Also, the viewpoint of some of the authors is a little narrow. Char advice on treatment is seldom given. What do statements such as "improved sleop 